\title{
Radiation effects of nuclear physics rays on hepatoma cells
}

https://doi.org/10.1515/phys-2019-0017

Received October 30, 2018; accepted January 28, 2019

\begin{abstract}
The traditional method of cloning formation is used to study the radiation effect of nuclear physics rays on hepatoma cells, and the results obtained are not reliable. Therefore, a new method of studying the radiation effect of nuclear physics rays on hepatoma cells is proposed. PCC method is used to study the radiation effect of $\gamma$-rays on hepatoma cells. Radiation effects of X-rays on hepatoma cells were studied by radionuclide formation assay, neutral comet electrophoresis and $\gamma \mathrm{H} 2 \mathrm{AX}$ focal detection. The results showed that the survival curves of HepG2 hepatoma cells irradiated by $\gamma$-rays were well fitted by linear squares. There was a linear relationship between the survival rate and irradiation dose of HepG2 hepatoma cells irradiated by $\gamma$-rays. HepG2 hepatoma cells showed strong tolerance to X-ray irradiation, and the positive rate of $\gamma \mathrm{H} 2 \mathrm{AX}$ cells reached $100 \%$ in each dose group only 0.5 $\mathrm{h}$ after X-ray irradiation.
\end{abstract}

Keywords: $\gamma$-ray, $\mathrm{x}$-ray, hepatoma cell, radiation effect, cloning formation method, electrophoresis detection, research

PACS: $21.65 .+\mathrm{f}, 28.41 . \mathrm{Te}, 29.30 . \mathrm{Kv}$

\section{Introduction}

Cancer is one of the most lethal diseases. Radiotherapy is currently one of the main means of liver cancer treatment. Radiobiologists study the radiation effects of different kinds of nuclear physics rays on hepatocellular carci-

\footnotetext{
${ }^{\star}$ Corresponding Author: Wenhui Zhao: College of Science, Harbin Engineering University, Harbin, 150001, China, E-mail: zhaowenhui1977@hrbeu.edu.cn Lu Cong: College of Information and Communication Engineering, Harbin Engineering University, Harbin, 150001, China,

E-mail: lu.cong@aliyun.com

Yolanda Guerrero-Sánchez: Departamento de Demartología, Estomatología y Medicna Física. Área de Medicina Bucal. Universidad de Murcia, Spain, E-mail: yolanda.guerreros@um.es
}

noma cells as the main objective to determine the radiation results and efficacy of different nuclear physics rays on hepatocellular carcinoma cells $[1,2]$. Accurate research on radiation effects of hepatocellular carcinoma cells can not only provide theoretical basis for cancer treatment, but also provide great help for clinicians in choosing treatment options. But the same treatment dose caused different damage to different tissues and cells [3]. Radiation effects of different nuclear physics rays on hepatocellular carcinoma cells are different in clinic, and the effects of radiotherapy are also very different.

Previous studies involving different cell lines and different types of radiation, such as X-rays, $\gamma$-rays and heavy ion beams, showed a linear dose-dependent relationship after radiation [4]. There are many methods to study the radiation effect of $\gamma$-rays on hepatocellular carcinoma cells. Cloning is a common method to study the radiation effect of hepatocellular carcinoma cells. However, as a conventional method, the results obtained by single cloning method are not reliable, and it is not suitable for clinical diagnosis and treatment [5]. Premature chromosome agglutination (PCC) technique was used to study the radiation effect of hepatocellular carcinoma (HCC), which took only 2 days from cell treatment to result statistics, but its application was limited. After chromosome damage, PCC technology has become a mature method to study radiationinduced primary chromosome damage in different cell cycle phases, especially in G2 phase [6]. However, most of the studies focused on G2 phase of hepatocellular carcinoma cells, and there were few reports on the correlation between G1 phase and G2 phase. There are few effective methods to study the radiation effect of X-ray on hepatoma cells, such as cloning, electrophoresis and so on [7].

In view of the shortcomings of the current research on $\mathrm{X}$-ray and $\gamma$-ray radiation to hepatoma cells, a new and effective method is adopted to re-study the radiation effects of X-ray and $\gamma$-ray $[8,9]$. The main methods were as follows: the radiation effects of human hepatoma HepG2 cells were studied by chemical-induced PCC technique. The radiation effects of X-rays on hepatocellular carcinoma cells were studied by cloning formation assay, neutral comet electrophoresis and $\gamma \mathrm{H} 2 \mathrm{AX}$ focal detection. The aim was 
to provide effective radiation methods for different nuclear physical rays on hepatocellular carcinoma cells in clinical radiotherapy.

\section{Material method}

\subsection{Materials and methods for studying the radiation effects of $\gamma$-rayson hepatocellular carcinomacells}

\subsubsection{Cell culture}

Human hepatoma cell HepG2 (purchased from CCTCC) was cultured in RMPI-1640 medium containing 10\% fetal bovine serum in a constant temperature incubator at $37^{\circ} \mathrm{C}$ and $5 \% \mathrm{CO}_{2}$.

\subsubsection{Cell irradiation}

HepG2 hepatoma cells in exponential growth stage were irradiated with $\gamma$-rays (dose rate $0.2 \mathrm{~Gy} / \mathrm{min}$ ) from Co source in a medical school.

\subsubsection{PCC method and chromosome preparation}

Calyculin-A (purchased from BIOMOL, USA) is a good inducer for PCC. It is dissolved in $100 \%$ ethanol and made into $1 \mathrm{mmol} / \mathrm{L}$ storage solution [10]. Before irradiation, it was added to the culture medium of irradiated cells, and the final concentration was $50 \mathrm{nmol} / \mathrm{L}$. After irradiation, the cells were cultured in a constant temperature incubator with $37^{\circ} \mathrm{C}$ and $5 \% \mathrm{CO}_{2}$ for 30 minutes. The cells were treated with $75 \mathrm{mMKCl}$ for 20 minutes and fixed with Carnot's solution [11]. At last, the cells were suspended in a small amount of stationary solution. The cells were dried in hot steam and stained with 5\% Giemsa.

\subsubsection{Chromosome observation and enumeration}

According to Savage's criteria, G2 phase cells at no less than 40 doses were observed and the number of chromatid breaks and isochromatid breaks were calculated. At the same time, the G1 phase cells in the process were recorded and the number of chromatid breakage was calculated. Each chromatid breakage is equal to two fractures.

\subsection{Materials and methods for studying the radiation effects of $X$-ray on hepatocellular carcinoma cells}

\subsubsection{Material}

Human hepatoma cell HepG2 is frozen in our central laboratory; DMEM (Dulbecco's modified Eagle medium) is from Gibco; MTT (3-(4, 5-Dimethylthiazol-2-yl) -2, 5diphenyltetrazolium bromide) is from Sigma; DAPI (4, 6diamino-2-phenyl indole) is from Molecular Probes; propidium iodide (4, 6-diamino-2-phenyl indole) is from Molecular Probes, USA. Propidium iodide, (PI) is provided by Lsbio Company of USA; mouse anti- $\gamma \mathrm{H} 2 \mathrm{AX}$ monoclonal antibody comes from Upstate Technology Company of USA; the other reagents are all domestic analytical purity.

Olympus AX70 fluorescence microscope is from Olympus Company of Japan; enzyme-linked immunoassay analyzer is from Bio-Rad Company of America; DYY-6C electrophoresis analyzer is from Beijing 61 Instrument Factory. The X-ray irradiation device is RX-650 Cabinet XRadiator System: the energy is $100 \mathrm{kVp}$ (Kilovolt peak, peak voltage); the current is $5 \mathrm{~mA}$; the absorbed dose rate is $1.38 \mathrm{~Gy} / \mathrm{min}$; the irradiation field is $20 \mathrm{~cm} \times 20 \mathrm{~cm}$.

\subsubsection{Method}

\section{Cell culture}

Human hepatoma cells were incubated in incubators incubated at 5\% CO2 and 37 degrees. The culture medium was DMEM containing 10\% inactivated calf serum and antibiotics $(100 \mu \mathrm{g} / \mathrm{mL}$ penicillin and $100 \mu \mathrm{g} / \mathrm{mL}$ streptomycin). Each 3-4d was passaged once, and logarithmic growth phase cells were used for the experiment.

\section{Cell grouping setup}

$\mathrm{X}$-ray irradiation was used to irradiate hepatocellular carcinoma cells with absorbed doses of $2 \mathrm{~Gy}, 4 \mathrm{~Gy}, 6 \mathrm{~Gy}$ and 8 $\mathrm{Gy}$, respectively. The experiment was carried out after irradiation for $0.5 \mathrm{~h}, 4 \mathrm{~h}$ and $24 \mathrm{~h}$ in non-irradiated group.

\section{Effect of X-ray on the radiation of human hepatoma cells} by colony formation assay.

The cells with concentration of $4 \times 108 \mathrm{~L}^{-1}$ were inoculated into the bottle of human hepatoma cells. The cells were incubated in $2 \mathrm{~mL}$ DMEM medium for 24 hours at $37^{\circ} \mathrm{Cand}$ for X-ray irradiation, then further culture at $37^{\circ} \mathrm{C} .0 .25 \%$ 
trypsin is used to digest cells and make single cell suspension. Cell suspension was diluted by gradient dilution and inoculated in a $100 \mathrm{~mm}$ diameter dish. Each dose group consisted of 4 dishes, with two cell density groups (except control group) (cell density: control group 5×102 / dish; 2 Gy group, $8 \times 102$ / dish and $4 \times 103$ / dish; 4 Gy group, $1 \times 103$ / dish and $5 \times 103$ / dish; 6 Gy group, $3 \times 103$ / dish and $1.5 \times 104$ / dish; 8 Gy group, $6 \times 103 /$ dish and $3 \times 104$ / dish), the final volume of each dish DMEM is $10 \mathrm{~mL}$. The cells were cultured for $10-14$ days in incubator at $37^{\circ} \mathrm{C}$ and $5 \%$ CO2. The incubator was discarded. Phosphate buffer saline (PBS) was carefully washed twice. The fixed solution (methanol: glacial acetic acid = 3:1) was fixed for 15 minutes. The fixed solution was discarded and dried. The cells were stained with $0.4 \%$ crystal violet for 20 minutes, with water washing and air drying [12]. The number of clones consisting of more than 50 cells was counted under an inverted microscope. The plating efficiency (PE) and survival fraction (SF) were calculated according to the Formula (1), (2).

$$
\begin{gathered}
P E=\frac{A C N}{N I C} \times 100 \% \\
S F=\frac{N C F A I}{N I C \times C F R U C} \times 100 \%
\end{gathered}
$$

In the form of Average number of clones is CAN, number of clones formed after irradiation is NCFAI, The number of inoculated cells is NIC, Colony formation rate of unirradiated cells is CFRUC.

\section{Detection of DNA double strand damage by neutral comet electrophoresis}

Digest and adjust the cell concentration to $4 \times 107 \mathrm{~L}-1.50 \mu \mathrm{L}$ $1 \%$ low melting point agarose gel was evenly spread on the glass slide and placed at room temperature [13]. The above $400 \mu \mathrm{L}$ cells and $1.2 \mathrm{~mL} 1 \%$ low melting point agarose gel were preheated at $40^{\circ} \mathrm{C}$, then mixed and quickly spread on the first layer of gel (about $1.4 \mathrm{~mL}$ ), and cured at room temperature for $3 \mathrm{~min}$. The slides were immersed in the newly prepared pre-cooled pyrolysis solution (containing $0.4-0.5 \mathrm{mg} / \mathrm{ml}$ protease $\mathrm{K}$, added before use), pyrolysis at $4^{\circ} \mathrm{C}$ for $1 \mathrm{~h}$, and carefully incubated in incubator at $37^{\circ} \mathrm{C}$ for 18-20 h; TBE buffer (45mmol/L Tris-boric acid; $1 \mathrm{mmol} / \mathrm{L}$ EDTA, $\mathrm{pH}=8.5$ ) was used to rinse the slides three times for 30 minutes each time. Place the slide in the electrophoresis tank for 30 minutes, pay attention that the liquid level should be $2 \mathrm{~mm}$ higher than the slide, and avoid light; adjust the buffer liquid level, so that the voltage is $16-18$ $\mathrm{V}$, current is about $7 \mathrm{~mA}$, electrophoresis time is $25 \mathrm{~min}$ utes. $1 \% \mathrm{H}_{2} \mathrm{O}_{2}$ is used to fix glass for 10 minutes, and fully washed by double distilled water. PI $(5 \mu \mathrm{g} / \mathrm{mL})$ is stained for 30 minutes, placed in an airtight wet box, stored at $4{ }^{\circ} \mathrm{C}$ (observed within 24 hours to prevent fluorescence quenching). Under the excitation of fluorescence microscope $(10 \times 40)$ ultraviolet (UV), the DNA image is orange red. Each slide was taken for at least 50 cells, and each drug dose was taken for 3 slides [14]. The images were analyzed by CASP software. The comet tail length, head DNA content, tail DNA content, tail moment (Talmoment, TM and Olive tail moment, OTM) were calculated. TM is defined as the product of the average distance of migration and the DNA fraction of comet tail [15]. OTM calculation: the distance between the center of gravity of the tail light density and the center of gravity of the head light density $x$ the percentage content of DNA in the tail.

\section{Immunofluorescence staining was used to detect the formation of $\gamma \mathrm{H} 2 \mathrm{AX}$ foci.}

The cells with a concentration of $2 \times 108 \mathrm{~L}-1$ were inoculated into a $35 \mathrm{~mm} \times 10 \mathrm{~mm}$ dish with a cover slide (soaked in $95 \%$ ethanol after cleaning and overheated, pre-placed in the dish). The cells were incubated at $37^{\circ} \mathrm{C}$ for $2 \mathrm{~h}$, added to DMEM medium for $2 \mathrm{~mL}$, and cultured for $24 \mathrm{~h}$. Remove the cover slides, pre-cool TBS buffer ( $25 \mathrm{mmol} / \mathrm{L}$ Tris, 137 $\mathrm{mmoL} / \mathrm{L}$ sodium chloride, $2.7 \mathrm{mmol} / \mathrm{L}$ potassium chloride) to wash twice, $4 \%$ paraformaldehyde is used to fix for 20 minutes; TBS washing for $5 \mathrm{~min} \times 3$ times; $0.2 \%$ Triton-X 100 is used to break film, the shaking table speed for $100 \mathrm{r} / \mathrm{min}$, $15 \mathrm{~min}$; TBS washing, $5 \mathrm{~min} \times 3$ times; TTN sealing solution (BSA, volume fraction, $1 \%$ TBS weight concentration, $0.2 \%$ Tween 20 ) was soaked for 10 minutes, PBS was washed for $5 \mathrm{~min} \times 3$ times, TTN diluted mouse $\gamma \mathrm{H} 2 \mathrm{AX}$ monoclonal antibody (1:500) was labeled and incubated for 2 hours, TBS was washed for $1 \mathrm{~min} \times 2$ times, TTN was washed for 1 min, TTN diluted goat anti-rat FITC-lgG (1:200), incubated for $1 \mathrm{~h}$ : TBS washed for $5 \mathrm{~min} \times 3$ times, and avoided light; DAPI $(0.05 \mu \mathrm{g} / \mathrm{mL})$ is stained for $5 \mathrm{~min}$, TBS washed for 5 $\min \times 3$ times, attention should be taken to avoid light; fixed fluid seals were observed under OlympusIX51 fluorescence microscope. The quantitative method of $\gamma \mathrm{H} 2 \mathrm{AX}$ focus was: the number of $\gamma \mathrm{H} 2 \mathrm{AX}$ focus was counted by image pro plus software, and the number of $\gamma \mathrm{H} 2 \mathrm{AX}$ focus was more than 5 positive cells. Each film counts at least 800 cells.

\section{Statistical analysis method}

The experimental data were expressed by $\bar{x} \pm \mathrm{s}$, and then analyzed by SPSS 11.5. The difference between the mean values of multiple groups was tested by one-way ANOVA. When $\mathrm{P}<0.05$, the results showed that the difference was statistically significant. 


\section{Results}

\subsection{Cell viability assay}

Figure 1 is the survival curve of HepG2 hepatoma cells irradiated by $\gamma$-rays. The fitting function is $S=\exp \left(-\alpha D-\beta D^{2}\right)$, and the correlation coefficient is $R^{2}=1, \alpha$ and $\beta$ are 0.03 and 0.06 , respectively. The $\beta$ value greater than the $\alpha$ value indicates that high dose radiation can better overcome the immediate effect of cell repair, and the survival rate decreases exponentially, unlike the linear attenuation in low dose radiation [16-22].

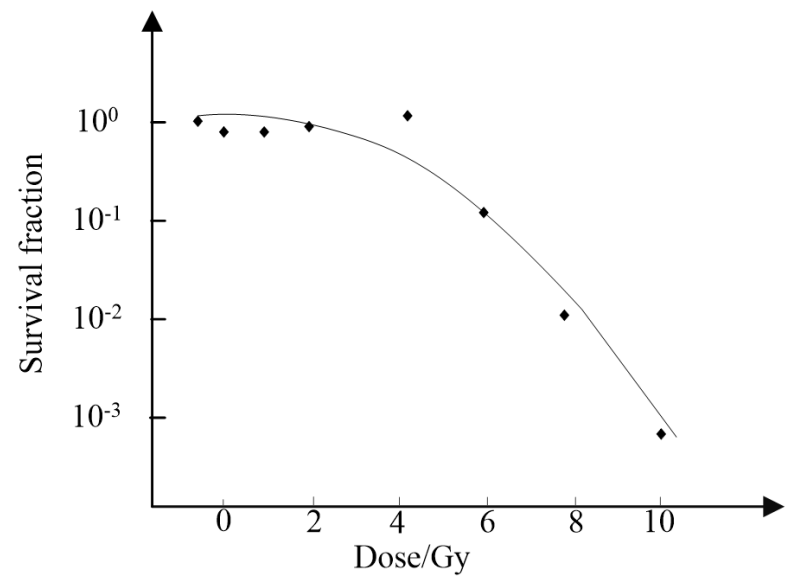

Figure 1: HepG2 hepatoma cell survival curve

\subsection{PCC induction efficiency}

Caly Culin A is a protein serine/tyrosine phosphatase inhibitor that can induce PCC formation at different stages of cell cycle, especially at G2 stage. Caly Culin A can induce premature chromosome agglutination in mixed cells at 50 $\mathrm{nm}$. Among the agglutinated chromosomes, about $20 \%$ of G1 phase cells and about $80 \%$ of G2 phase cells. The proportion of these two phase cells is called PCC induction efficiency. At each dose point, when $40 \mathrm{G} 2$ phase cells were counted, 5-8 G1 phase cells entered the counting range, indicating that the induction efficiency of PCC in this experiment was $12.5 \%-20 \%$, the results are shown in Table 1.
Table 1: Data ratio of G1 and G2 precocious chromosome agglutination cells

\begin{tabular}{lllllllll}
\hline Dose/Gy & 0 & 0.5 & 1 & 2 & 4 & 6 & 8 & 10 \\
\hline G1 cells & 7 & 6 & 5 & 5 & 6 & 8 & 7 & 8 \\
G2 cells & 40 & 40 & 40 & 40 & 40 & 40 & 40 & 40 \\
G1/G2(\%) & 17.515 & 12.512 .515 & 20 & 17.5 & 20 \\
\hline
\end{tabular}

\subsection{Chromatid breakage after irradiation of Gl and G2 Cells}

Figure 2 shows the relationship between G1 and G2 cell chromatid breakage and irradiation dose. As can be seen from Figure 2, the number of chromatid breaks increases linearly with the dose at G1 and G2 stages. At the same dose point, the number of $\mathrm{G} 2$ phase chromatids is about 3 to 4 times that of $\mathrm{G} 1$.

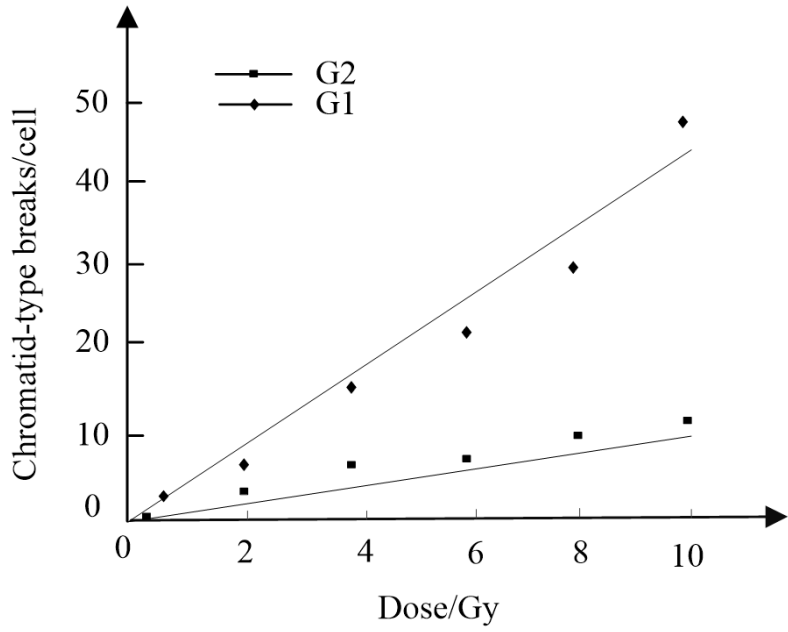

Figure 2: Dose effect relationship between G1 and G2 chromatid breakage

\subsection{G2 phase isochromatid breakage}

Figure 3 is the relationship between the chromatid breakage and the dose of G2 isochromatic cells. By linear regression analysis, the regression equation is $y=0.01+0.2 x$, $R^{2}=0.99$, indicating that there is a good linear correlation between the two. 


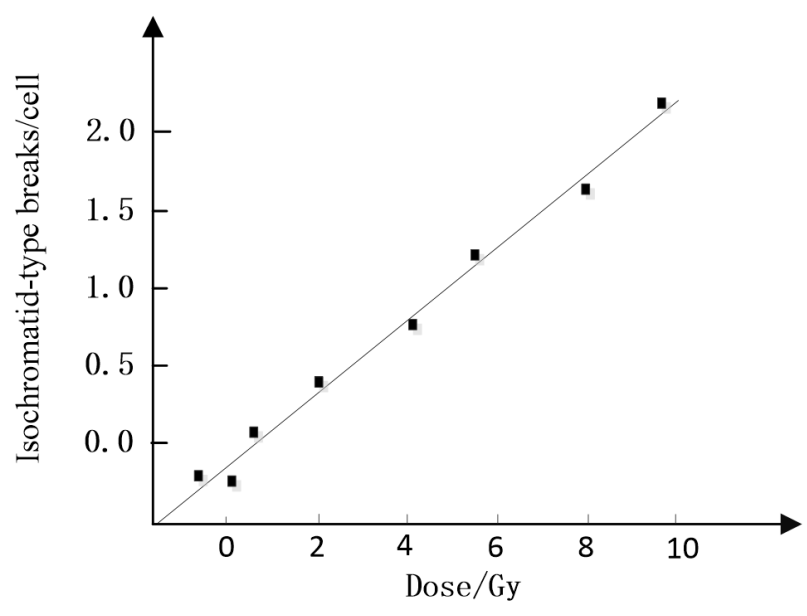

Figure 3: Dose effect relationship of G2 phase isochromosome chromosome breakage

\subsection{Relationship between chromatid breakage and cell survival fraction}

Figure 4 is the relationship between the number of $\mathrm{G} 2$ chromatid breakup and the number of chromatid breakpoints and cell survival. Linear regression analysis showed that there was a good correlation between the number of chromatid and isochromatid breaks and cell survival rate in G2 phase cells.

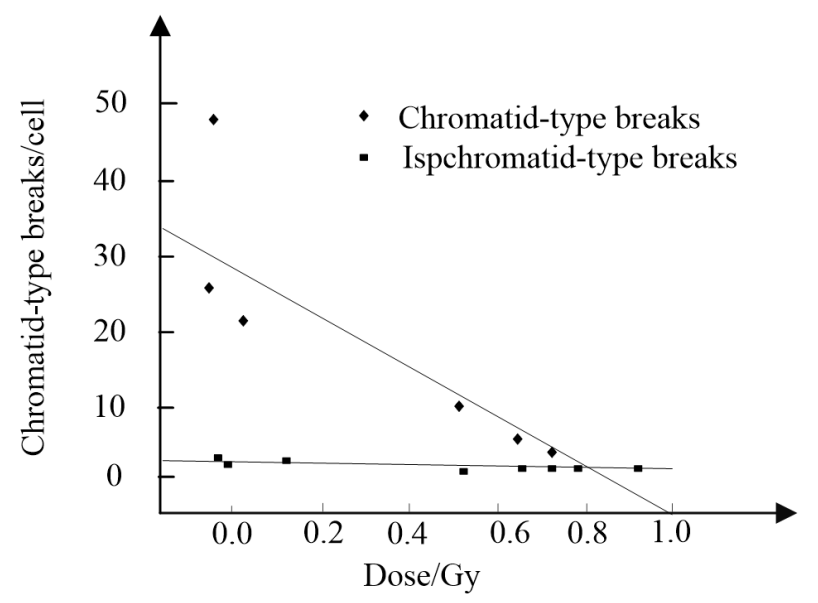

Figure 4: Relationship between G2 chromatid breakup and isochromatid breakage and cell survival rate

\subsection{X-ray inhibits proliferation of HepG2 hepatoma cells}

The results of clone formation assay showed that the survival fraction of HepG2 hepatoma cells decreased in a dose-dependent manner ( $\mathrm{p}<0.05)$ from 2, 4, 6, 8 Gy to 0.5, 4 and $24 \mathrm{~h}$ after X-ray irradiation. At 4 and $24 \mathrm{~h}$ after irradiation, the survival fraction of each dose group recovered, as shown in Figure 5.

\subsection{X-ray induced DNA double strand damage in HepG2 hepatoma cells}

The results of neutral comet electrophoresis showed that 0.5 , 4, and $24 \mathrm{~h}$ after irradiation of Hela, MEC-1 and HepG2 cells with X-ray irradiation of 2, 4, 6, $8 \mathrm{~Gy}$, the three cells showed typical changes of comet cell indices. At $0.5 \mathrm{~h}$ after irradiation, TM in each dose group increased significantly, and the $4 \mathrm{~h}$ group had the highest value after irradiation. Among them, the TM of MEC-1 cells increased significantly at 4 hours after irradiation, reaching 84.56 in 6 Gy irradiation group, while the TM of Hela cells increased relatively little, which was significantly different from that of MEC-1 cells and HepG2 hepatoma cells ( $p<0.05)$; at 24 hours after irradiation, the TM values of each dose group decreased in varying degrees (Figure 6, Table 2).

\subsection{X-ray induced $\gamma \mathrm{H} 2 \mathrm{AX}$ formation has time and dose effects}

Immunofluorescence staining showed that the focal $\gamma \mathrm{H} 2 \mathrm{AX}$ was expressed in different degrees at $0.5,4$ and $24 \mathrm{~h}$ after irradiation of HepG2 hepatoma cells to 2, 4, 6, $8 \mathrm{~Gy}$. After $0.5 \mathrm{~h}$, the green fluorescent focus appeared in the nuclei of HepG2 hepatoma cells, as shown in Figure 7. Compared with the control group, the percentage of $\gamma \mathrm{H} 2 \mathrm{AX}$ positive cells in HepG2 hepatoma cells increased significantly at $0.5,4$ and 24 hours after irradiation $(\mathrm{p}<$ 0.05). The percentage of $\gamma \mathrm{H} 2 \mathrm{AX}$ positive cells in HepG2 hepatoma cells reached $100 \%$ at 0.5 hours after irradiation in 2 Gy group, and decreased gradually at 24 hours after irradiation, but there was still significant difference compared with the control group $(\mathrm{p}<0.05)$, as shown in Figure 8. 
Table 2: Comparison of TM in three cell lines at different time points after X-ray irradiation

\begin{tabular}{llllll}
\hline \multicolumn{1}{c}{ Groups } & \multicolumn{4}{c}{ Dose $/$ Gy } \\
& 0 & 2 & 4 & 6 & 8 \\
\hline MEC-1/Hela at $0.5 \mathrm{~h}$ & $20.13 / 17.33$ & $20.32 / 20.10$ & $24.35 / 22.51$ & $38.38 / 23.47^{\star}$ & $41.32 / 20.98^{\star \star}$ \\
MEC-1/Hela at 4h & $20.13 / 17.33$ & $54.21 / 23.37^{\star \star}$ & $68.28 / 33.41^{\star \star}$ & $84.56 / 34.89^{\star \star}$ & $81.27 / 33.56^{\star \star}$ \\
MEC-1/Hela at 24h & $20.13 / 17.33$ & $19.16 / 20.93$ & $20.85 / 20.51$ & $31.97 / 20.27^{\star}$ & $30.23 / 19.70^{\star}$ \\
MEC-1/HepG2 at 0.5h & $20.13 / 17.91$ & $20.32 / 30.59^{\star}$ & $24.35 / 40.20^{\star}$ & $38.38 / 44.18^{\star}$ & $41.32 / 42.49$ \\
MEC-1/HepG2 at 4h & $20.13 / 17.91$ & $54.21 / 33.53^{\star}$ & $68.28 / 41.70^{\star \star}$ & $84.56 / 51.77^{\star \star}$ & $81.27 / 47.40^{\star \star}$ \\
MEC-1/HepG2 at 24h & $20.13 / 17.91$ & $19.16 / 19.62$ & $20.85 / 21.85$ & $31.97 / 23.62^{\star}$ & $30.23 / 22.15^{\star}$ \\
Hela/HepG2 at 0.5h & $17.33 / 17.91$ & $20.13 / 30.59^{\star}$ & $22.51 / 40.20^{\star}$ & $23.47 / 44.18^{\star}$ & $20.98 / 42.49^{\star}$ \\
Hela/HepG2 at 4h & $17.33 / 17.91$ & $23.37 / 33.53^{\star}$ & $33.41 / 41.70^{\star \star}$ & $34.89 / 51.77^{\star}$ & $33.56 / 47.40^{\star}$ \\
Hela/HepG2 at 24h & $17.33 / 17.91$ & $20.93 / 19.62$ & $20.51 / 21.85$ & $20.27 / 23.62^{\star \star}$ & $19.70 / 22.15$ \\
\hline
\end{tabular}

\section{Disscusions}

\subsection{Discussion on the radiation effects of $\gamma$-rays on hepatoma cells}

Radiotherapy is currently one of the main means of cancer treatment. The radiation effects of cancer cells on radiotherapy are affected by various factors. Caly Culin A is an effective inducer of PCC. It can induce chromosome aggregation at various stages of cell cycle, especially at $\mathrm{G} 2$ stage. In this study, we found that Caly Culin A induced chromosome aggregation in G2 phase was 5-8 times as efficient as that in G1 phase, which was consistent with Goodwin's and Durante's results, but its mechanism needs further study. In this study, the linear relationship between cell survival rate and irradiation dose of HepG2 hepatoma cells irradiated by $\gamma$-rays has been confirmed by many studies. At G1 and G2 stages, the increase of the number of chromatid breaks was linearly correlated with the decrease of cell viability.

In our study, both the number of chromatid breaks and the isochromatid breaks in HepG2 hepatocellular carcinoma cells linearly increased with the increase of the dose of $\gamma$-rays, suggesting that at higher doses, more electrons would hit the target substance - the chromosome, so the yield of chromosome breaks would increase in response.

However, the absolute increment of G2 isochromatid breakage in HepG2 hepatoma cells was much less than that of chromatid breakage. After studying the biological effects of different LET rays, chromosome breakage was mainly caused by chromatid breakage, while in high LET irradiation, isochromatid breakage was the main form of chromosome breakage, probably because most isochromatid breaks were caused by isochromatid breakage. The body fracture is caused by the electron hitting sister chromatid. For low LET radiation, it loses not enough energy per unit range to cause sister chromatid breakage, so after hitting one of the sister chromatids, the energy loss is exhausted or the remaining energy is insufficient to cause damage to another chromatid. Therefore, after low LET ray irradiation, chromosome breakage is mostly chromatid breakage.

In the G1 phase of HepG2 hepatocellular carcinoma cells, chromosomes are relatively loose aggregated, but in the G2 phase of HepG2 hepatocellular carcinoma cells, the aggregation of chromosomes is much tighter than in the G1 phase because of the replication of chromosomes and the preparation for mitosis. Therefore, the same energy of $\gamma$ rays on chromosome cross section is greater than $\mathrm{G} 1$, and the G2 chromosome breakage yield will be higher than G1.

\subsection{Discussion on the radiation effects of $\mathrm{X}$-ray on hepatocellular carcinoma cells}

The results of cloning formation showed that SF of HepG2 hepatoma cells increased with the time after irradiation. These results indicate that HepG2 hepatoma cells are highly resistant to X-rays. Further studies have shown that the radiation effect of HCC cells on radiation is closely related to the degree of DNA damage and repair ability of the cells. It is generally believed that radiation can directly lead to DNA damage, and at the same time make the cells and the water between cells ionized, producing a large number of oxygen free radicals, indirectly produce DNA damage and then lead to cell death. The most serious type of DNA damage is DNA double strand breaks (DSB), if not repaired in time, it can cause chromosome translocation, genetic information loss, and even cell death. DNA damage detection methods include fluorescence in situ hy- 


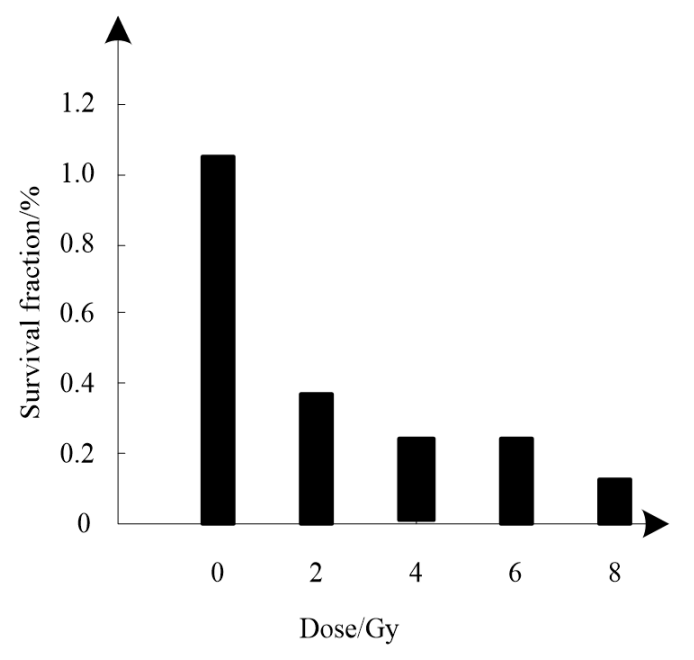

(a) $0.5 \mathrm{~h}$ after irradiation

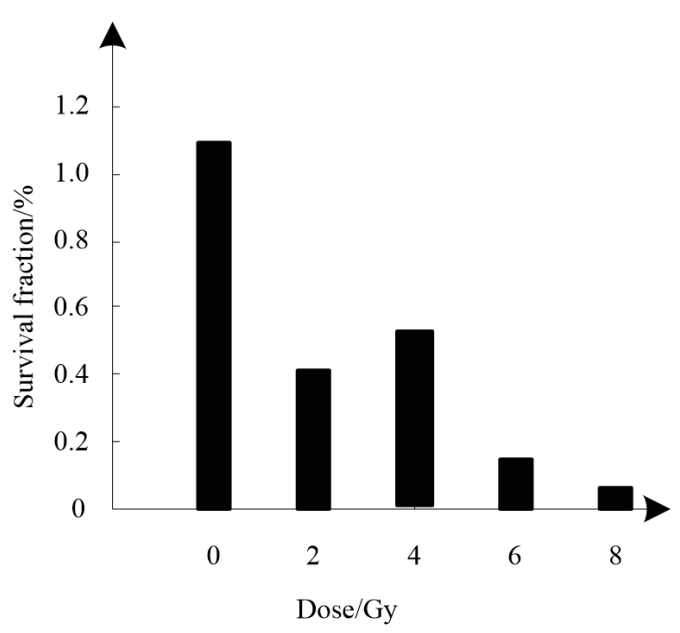

(b) $4 \mathrm{~h}$ after irradiation

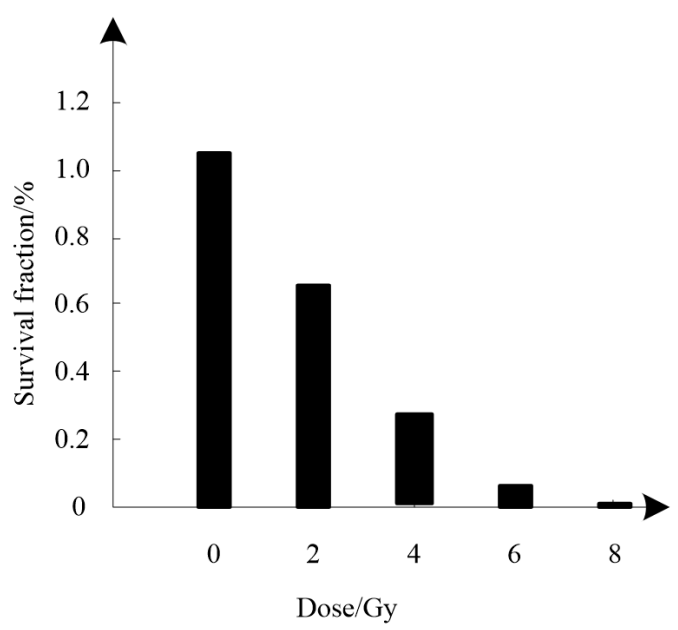

(c) $24 \mathrm{~h}$ after irradiation

Figure 5: Effect of X-ray on the clone formation of HepG2 hepatoma cells bridization, comet assay, high performance capillary electrophoresis, sequence gel electrophoresis and so on. Neutral comet assay is widely used in DSB detection. TM was used as the index of comet assay. The results showed that DSB of HepG2 hepatoma cells induced by X-ray showed a time-and dose-dependent relationship, and the change of TM was most obvious at 4 hours after irradiation. Among them, 4 hours after irradiation, the TM value of 6 Gy group was 84.56, indicating that compared with HepG2 and HeLa cells, MEC-1 cells were most sensitive to X-ray irradiation ( $\mathrm{p}$ $<0.05$ ); for HepG2 and HeLa cells, 4 hours after irradiation, the TM value of HepG2 was higher than that of HeLa cells $(\mathrm{p}<0.05)$.

DNA damage response (DDR) is an exceptionally complex regulatory system in DNA. When ionizing radiation causes DSB, members of the phosphatidylinositol-3kinase family: ATM (Ataxia telangiectasia mutatedgene), ATR (Ataxia-telangiectasia and Rad-3related) and DNA-PK (DNA-dependent protein kinase) are activated, mobilizing a series of phosphorylation cascades, activating the stress system, and activating the DDR signal. Downstream molecules of the pathway, such as $\gamma \mathrm{H} 2 \mathrm{AX}$, MRN, Chk2 and $\mathrm{p} 53$, repair DNA, produce cell cycle arrest or initiate apoptosis. The results showed that phosphorylated histone $\mathrm{H} 2 \mathrm{AX}(\gamma \mathrm{H} 2 \mathrm{AX})$ was the index reflecting the radiation effect of DSB, and the focal point of $\gamma \mathrm{H} 2 \mathrm{AX}$ was one-toone corresponding to the quantity of DSB. The $\gamma \mathrm{H} 2 \mathrm{AX}$ fluorescence staining was the gold standard for detecting the presence of DSB. In this paper, a series of studies on $\gamma \mathrm{H} 2 \mathrm{AX}$ as radiation and chemotherapeutic radiation effect indicators have been carried out. It has been proved that $\gamma \mathrm{H} 2 \mathrm{AX}$ is an effective research parameter for studying radiation effect of radiotherapy and chemotherapy.

The expression of H2AX was detected by immunofluorescence staining. This method can directly count the number of focal points formed by $\gamma \mathrm{H} 2 \mathrm{AX}$, which is more convenient and sensitive than the traditional DSB method. The results showed that only $0.5 \mathrm{~h}$ after irradiation, the positive rate of $\gamma \mathrm{H} 2 \mathrm{AX}$ cells reached $100 \%$ in each dose group, and the high expression rate of $\gamma \mathrm{H} 2 \mathrm{AX}$ cells persisted until $4 \mathrm{~h}$ after irradiation; $24 \mathrm{~h}$ after irradiation, the positive rate of $\gamma \mathrm{H} 2 \mathrm{AX}$ cells in HepG2 hepatoma cells gradually decreased, but there was still significant difference compared with the control group.

\section{Conclusions}

PCC method was used to study the radiation effect of $\gamma$-rays on hepatocellular carcinoma cells. Clone formation assay, 

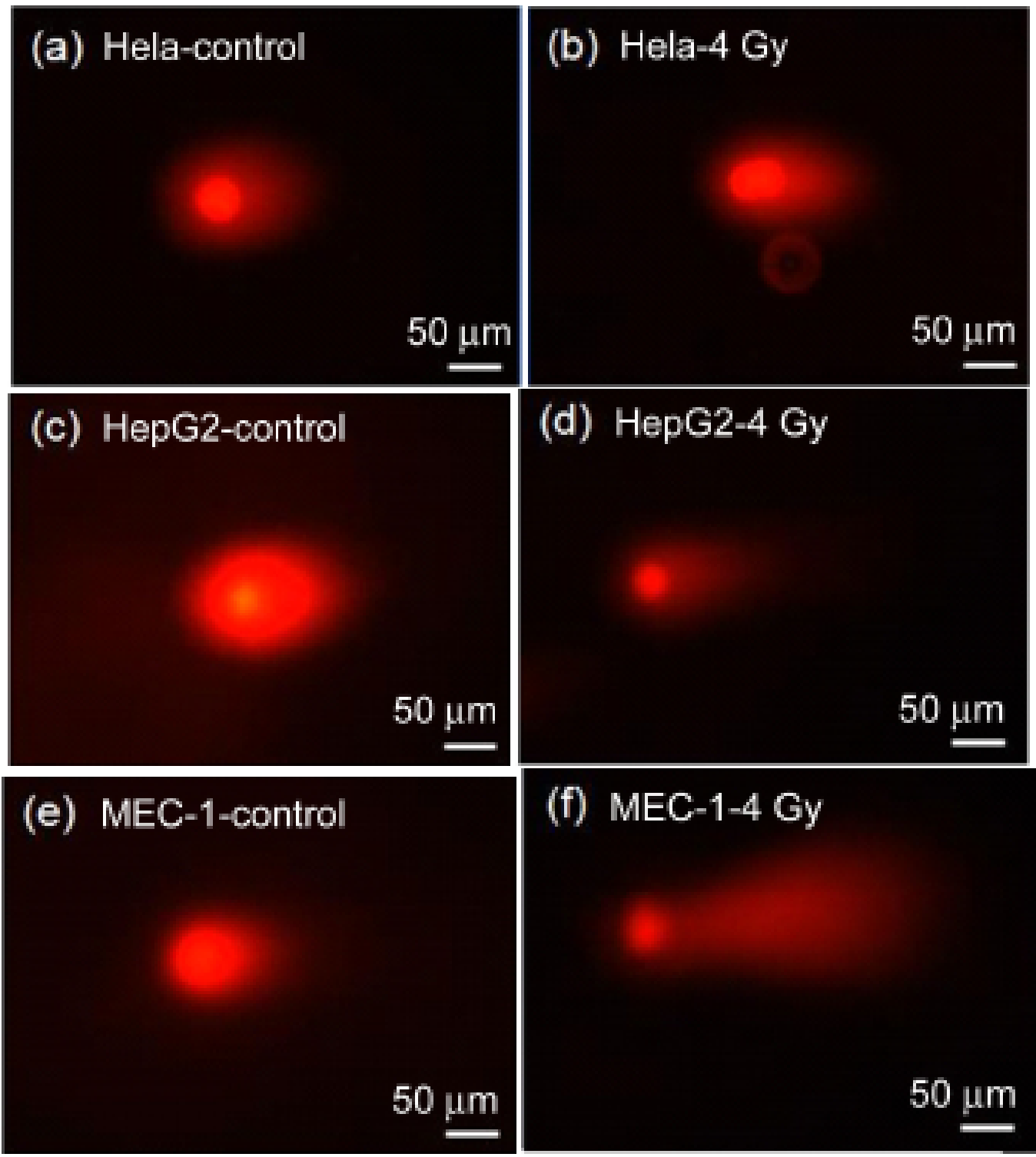

Figure 6: Neutral comet electrophoresis of $4 \mathrm{H}$ cells after $\mathrm{X}$-ray irradiation

neutral comet electrophoresis and $\gamma \mathrm{H} 2 \mathrm{AX}$ focal point detection were used to study the radiation effect of X-rays on hepatocellular carcinoma cells.

It is suggested that the linear growth of G2 phase chromatid breaks in HCC cells suggests a close correlation with radiation exposure of the cell line. Radiation effects of $\gamma$ rays on hepatoma cells showed that there was a linear correlation between the number of chromatid breaks and the isochromatid breaks in G1 and G2 phase cells and the dose of irradiation. There was a good linear correlation between the total number of chromatid breaks and the cell survival rate, indicating that radiation-induced chromatid breaks could be used as a precursor. The measurement of the internal radiation of hepatoma cells can also provide a basis for clinical diagnosis and treatment of liver cancer. X-ray irradiation showed that HepG2 hepatoma cells had a strong tolerance to X-ray irradiation. The DSB of HepG2 hepatoma cells was time-and dose-dependent, and the change of TM was most obvious at 4 hours after irradiation. The positive rate of $\gamma \mathrm{H} 2 \mathrm{AX}$ cells reached $100 \%$ in all irradiation doses and $100 \%$ after irradiation only 0.5 hours. The high expression rate lasted until 4 hours after irradiation, and the positive rate of $\gamma \mathrm{H} 2 \mathrm{AX}$ in HepG2 hepatoma cells decreased gradually 24 hours after irradiation. Radiotherapy is a very effective method of cancer treatment, for clinicians and patients, early diagnosis and treatment is very important. Chemically induced precocious chromosome agglutination technology has been widely applied. This 

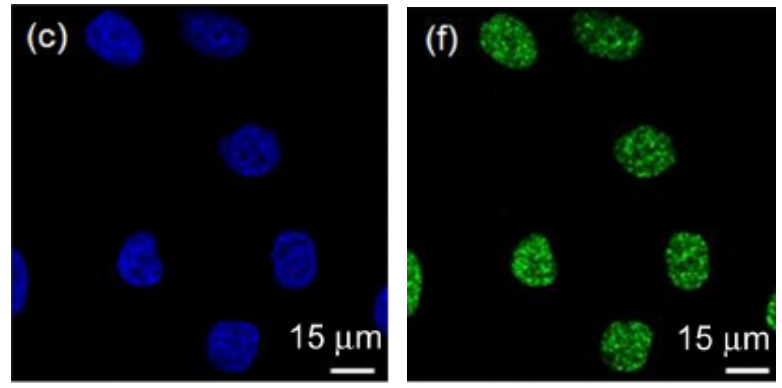

(a) DAPI

(b) $\gamma \mathrm{H} 2 \mathrm{AX}$

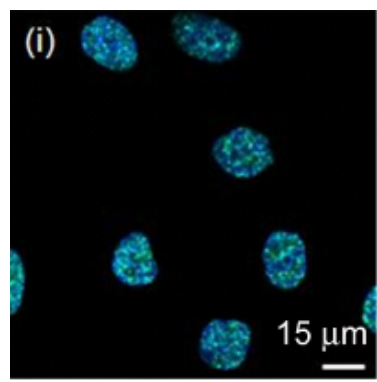

(c) Merge

Figure 7: HHepG2 hepatoma cells $X$ radiation of 8 Gy group after $0.5 \mathrm{~h}$ focus image formation

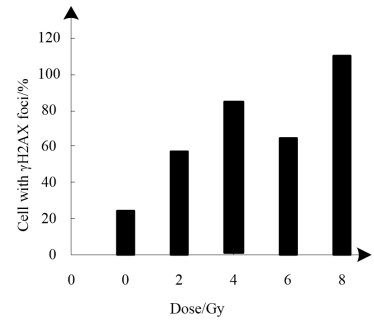

(a) $0.5 \mathrm{~h}$ after irradiation

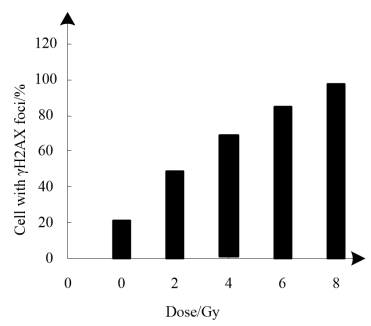

(c) $24 \mathrm{~h}$ after irradiation

Figure 8: Time and dose effect of $\gamma \mathrm{H} 2 \mathrm{AX}$ focus formation in HepG2 hepatoma cells after $\mathrm{X}$-ray irradiation

study provides a useful reference for clinical radiotherapy of liver cancer.

According to the radiation effects of nuclear physics ray on hepatoma cells, the application prospects are as follows:
Radiation therapy for nuclear physics is as a downstage treatment before liver transplantation. Liver transplantation is one of the most effective treatment methods for patients with early liver cancer, which can eliminate liver cancer, reduce the risk of disease progression and metastasis, and is conducive to the recovery of liver function. Liver transplantation should try to choose the limited lesion, and it is expected to get better survival after liver transplantation. Local treatment such as TACE, RFA and TACE can reduce the survival rate of $24 \%$ to $69 \%$ of patients who do not meet the transplantation criteria, and the survival rate of patients who do liver transplantation after the transplantation is better than those who do liver transplantation directly.

Radiation therapy is combined with immunotherapy for nuclear physics. Immunotherapy, as a new method of liver cancer treatment, has not made breakthroughs in liver cancer. Recent studies have shown that radiotherapy is a double-edged sword for immunity. In addition to immunosuppressive effect, radiotherapy has more prominent immune promoting effect in the process of liver cancer and normal tissue damage. Radiotherapy not only elicits local immune responses, but also produces a "distant effect", i.e. the phenomenon that liver cancer shrinks or disappears automatically with the disappearance of the irradiated liver cancer outside or far from the irradiated area. It is reported that many kinds of liver cancer have found "distant effects", such as malignant melanoma, advanced renal cancer, metastatic liver cancer, advanced lung cancer and advanced breast cancer.

Combination of radiation therapy and sensitizing drugs in nuclear physics. Patients with advanced hepatocellular carcinoma (HCC) have rapid progression, short survival time, and poor effects of chemotherapy and radiotherapy alone. Theoretically, combined use of radiotherapy and chemotherapy may improve the therapeutic effect. SHARP and Oriental studies are two large prospective randomized studies, not only confirmed the survival benefits of sorafenib in patients with advanced liver cancer, but also demonstrated its safety. The efficacy of sorafenib in the treatment of advanced liver cancer provides a basis for multidisciplinary treatment of liver cancer based on sorafenib. Since Sorafenib was approved by the Food and Drug Administration of the United States and the European Drug Evaluation Agency (EMEA) as a targeted molecule drug for the treatment of liver cancer in 2007, several clinical guidelines for liver cancer have recommended Sorafenib as a standard first-line treatment for patients with inoperable or advanced liver cancer, and a combination of multiple sorafenib and RT for clinical purposes. The experiment is under way. Among them, RTOG1112 is an ex- 
ploratory study of sorafenib combined with stereotactic radiotherapy in patients with middle-term liver cancer in Europe and America. Nearly 400 patients with unresectable liver cancer who are not suitable for TACE were randomly divided into solafenib group and somatic stereotactic radiotherapy plus solafenib group. The results are expected.

Acknowledgement: This research has been financed by the International Science \& Technology Cooperation Program of China (2014DFE10030).

\section{References}

[1] Binda A., Panariti A., Barbuti A., Murano C., Magro R.D., Masserini M.,et al.,Modulation of the intrinsic neuronal excitability by eultifunctional eiposomes eailored for the ereatment of Alzheimer's eisease, Int. J. Nanomed., 2018, 13, 40594071.

[2] Suh S.W., Choi Y.S., Predictors of micrometastases in patients with barcelona clinic liver cancer classification b hepatocellular carcinoma, Yonsei Med. J., 2017, 58(4), 737-742.

[3] Mei K., Du L., Yan M., Zhang Z., Zhang F., Gong L., et al., Modified leukocyte filter removes tumor cells from the salvaged blood, Plos One, 2015, 10(6), e0130864.

[4] Ikuta N., Chikamoto K., Asano Y., Yasui Y., Yokokawa H., Terao K., et al., Time course effect of $\mathrm{r}$-alpha-lipoic acid on cellular metabolomics in cultured hepatoma cells, J. Med. Food, 2017, 20(3), 211.

[5] Marques L.A., Semprebon S.C., Sartori D.DE Fátima Â., Ribeiro L.R., Mantovani MS., Comparison of the effects of monastrol and oxomonastrol on human hepatoma cell line HepG2/C3A, Anticanc. Res., 2017, 37(3), 1197.

[6] Huo Y., Wang LQ., Chen C., Solution of medium power gridconnected PV inverter radiation emission, J. Pow. Supp., 2016, 14(1), 109-113.

[7] Zhang M.X., Xu X.M., Zhang P.Han N.N., Deng J.J., Yu T.T., et al., Effect of silencing NEK2 on biological behaviors of HepG2 in human hepatoma cells and MAPK signal pathway, Tumor Biol., 2016, 37(2), 2023-2035.

[8] Tomita M., Maeda M., Mechanisms and biological importance of photon-induced bystander responses: Do they have an impact on low-dose radiation responses, J. Radiat. Res., 2016, 56(2), 205-219.

[9] Liu L.X., Deng W., Zhou X.T., Chen R.P., Xiang M.Q., Guo Y.T., et al., The Mechanism of adenosine-mediated activation of IncRNA MEG3 and its antitumor effects in human hepatoma cells, Int. J. Oncol., 2016, 48(1), 421-9.
[10] Lazzarini A., Macchiarulo A., Floridi A., Coletti A., Cataldi S., Codini M., et al., Very-long-chain fatty acid sphingomyelin in nuclear lipid microdomains of hepatocytes and hepatoma cells: Can the exchange from C24:0 to C16:0 affect signal proteins and vitamin D receptor, Mol. Biol. Cell, 2015, 26(13), 2418-2425.

[11] Wang W., Mei X., Duan X., Wang Y., Kong F., Delivery of baicalein and paclitaxel using self-assembled nanoparticles: synergistic antitumor effect in vitro and in vivo, Int. J. Nanomed., 2015, 10, 3737-3750.

[12] Horng C.T., Chou C.T., Tseng H.W., Cheng J.S., Chang H.T., Chang P.M., et al., Effect of methoxychlor on $\mathrm{Ca}^{2}+$ homeostasis and apoptosis in HA59T human hepatoma cells, Chinese J. Physiol., 2015, 58(1), 1-8.

[13] Zeng Z.C., Dong Y., Activation of JNK-c-Jun pathway in response to irradiation leads to fas ligand secretion in hepatoma cells which promotes hepatocytes injury via paracrine, Int. J. Radiat. Oncol. Biol. Phys., 2016, 96(2), 559-560.

[14] Cheon G.J., Kim K.H., Park J.Y.,Lee D., Jang H.J., Kwak J.H., et al., Caspase-mediated apoptotic effects of diol-type ginseng sapogenins on human hepatoma cell lines, Bullet. Korean Chem. Soc., 2015, 36(1), 431-434.

[15] Wang H., Guan X., Lu C.Based on the improved grey relational algorithm platform for the airborne radar emitter recognition method, J. China Acad. Electr. Inform. Technol., 2015, 10(5), 523526.

[16] Lee M.J., Lee S.J., Yun S.J., Jang J.Y., Kang H., Kim K., et al., Silver nanoparticles affect glucose metabolism in hepatoma cells through production of reactive oxygen species, Int. J. Nanomed., 2016, 11, 55-68.

[17] Wahi N., Bhatia A.K., Bhadauria S., Impact of protozoan vahlkampfia sp on the growth of algae chlorella vulgaris glamtr, J. Envir. Biol., 2018, 39(1), 109-115.

[18] Pomponi F., Lenzen M., Hybrid life cycle assessment (LCA) will likely yield more accurateresults than process-based LCA, J. Clean. Prod., 2018, 176, 210-215.

[19] Caraballo T., Diop M.A., Mane A., Controllability for neutral stochastic functional integrodifferential equations with infinite delay, Appl. Math. Nonlin. Sci., 2016, 1(2), 493-506.

[20] Liu Z., China's plans and policies for reducing Co2 emission from biomass-fired power plants: modeling and economic study, Ener. Sourc. Part B-Econom. Plan. Policy, 2017, 12(11), 1001-1006.

[21] Esteban M., Núñez E.P., Torres F., Bifurcation analysis of hysteretic systems with saddle dynamics, Appl. Math. Nonlin. Sci., 2017, 2(2), 449-464.

[22] Gao W., Baig A.Q., Ali H., Sajjad W., Farahani M.R., Margin based ontology sparse vector learning algorithm and applied in biology science, Saudi J. Biol. Sci., 2017, 24(1), 132-138. 